Short communication

\title{
Tailoring microstructure, tensile properties and fracture process via transient directional solidification of Zn-Sn alloys
}

\author{
Washington L.R. Santos ${ }^{\mathrm{a}, \mathrm{b}}$, Clarissa B. Cruz ${ }^{\mathrm{a}}$, José E. Spinelli ${ }^{\mathrm{c}, *}$, Noé Cheung ${ }^{\mathrm{a}}$, Amauri Garcia ${ }^{\mathrm{a}}$ \\ a Department of Manufacturing and Materials Engineering, University of Campinas - UNICAMP, 13083-860 Campinas, SP, Brazil \\ ${ }^{\mathrm{b}}$ Universidade Estadual Paulista - UNESP, 18409-010 Itapeva, SP, Brazil \\ ${ }^{c}$ Department of Materials Engineering, Federal University of São Carlos - UFSCar, 13565-905 São Carlos, SP, Brazil
}

\section{A R T I C L E I N F O}

\section{Keywords:}

Zn-Sn alloys

Solidification

Eutectic

Mechanical properties

Fracture

\begin{abstract}
A B S T R A C T
The aim of the present study is to determine interrelations of microstructure length-scale, tensile properties and fracture mechanisms of hypoeutectic Zn-Sn alloys. Three compositions were subjected to transient directional solidification: Zn-10, 20 and $40 \mathrm{wt} \% \mathrm{Sn}$. Grainy-faceted cleavage has been observed as the predominant mode of fracture, which propagated across the Zn-rich plate cells. A clear influence of the formed microstructure and proportion of eutectic may be noted in the fracture features, with alveolar structures also appearing in fracture surfaces. Growth laws relating the eutectic spacing with the growth rate are proposed, which are able to encompass both steady-state and transient solidification conditions. Hall-Petch type equations are developed relating the yield and ultimate tensile strengths, $\sigma_{\mathrm{y}}$ and $\sigma_{\mathrm{u}}$, respectively, to the cellular spacing, $\lambda$, in which smaller $\lambda$ values resulted in higher $\sigma_{\mathrm{y}}$ and $\sigma_{\mathrm{u}}$.
\end{abstract}

\section{Introduction}

Although sufficient information is available about important trends regarding the relationship between mechanical properties and microstructure of $\mathrm{Zn}-\mathrm{Al}$ alloys, information on $\mathrm{Zn}-\mathrm{Sn}$ alloys is scarce in the literature. These alloys have recently been considered alternatives to replace pewter alloys (malleable metals) in the giftware industry due to their excellent mechanical properties and lower cost [1]. Zn alloys offer many benefits as compared to other types of alloys, which include cleanliness, low temperature processing, excellent castability, high mechanical strength and superior wear properties [2]. Zn-Sn alloys are also considered $\mathrm{Pb}$-free solders alternatives to replace $\mathrm{Pb}-\mathrm{Sn}$ alloys. Here, a variety of applications is possible: assembling optical parts, circuit boards in automobiles and circuit modules for step soldering [3].

Among the $\mathrm{Zn}$-Sn alloys, the addition of tin at $20 \mathrm{wt} \%$ is commonly adopted. Santos et al. [3] characterized the microstructure along the length of a directionally solidified Zn-20 wt\%Sn alloy casting, which has been reported to be formed by an alternate pattern of elongated $\alpha$ Zn plate-like cells and an intercellular eutectic mixture. Oppositely, the addition of minor content of $\mathrm{Ag}(0.5 \mathrm{wt} \%)$ to the $\mathrm{Zn}-20 \mathrm{wt} \% \mathrm{Sn}$ alloy has been shown to inhibit the uniform $\mathrm{Zn}$-Sn eutectic to be formed [1]. The eutectic was mainly replaced with Ag-Sn compounds. Consequently, increase in tensile strength and ductility was attained [1].

Despite the studies existing in the literature on microstructure and mechanical properties of $\mathrm{Zn}-\mathrm{Sn}$ alloys [4-7], there is no indication of studies emphasizing the effects of varying solidification cooling rate and alloy Sn content on microstructure, mechanical properties and fracture mechanisms. This would permit appropriate coupling of cooling rate/Sn content (processing parameters), cell/eutectic spacing (microstructure parameters) and mechanical behavior (application properties).

In polycrystalline materials, propagation of a cleavage crack from grain to grain is a complex process [8]. The well-defined planes of cleavage of each grain do not match each other in their common grain boundary. Additional failure mechanisms are involved, such as the presence of brittle grain boundary fracture between two cleavage paths and localized ductile failure at the boundaries. According to Giallourakis et al. [9], in polycrystalline zinc coatings the size of the cleavage facets can be correlated with the grain size of the specimen. However, to the authors' knowledge, the effects of subgrain structures such as cells, dendrites and eutectics on the mode of fracture remain undetermined.

In the case of binary Zn-Sn alloys, the eutectic structure develops along the boundaries of the primary Zn-rich grains. Considering that, according to the $\mathrm{Zn}$-Sn phase diagram, the eutectic composition is $\mathrm{Zn}$ $91.2 \mathrm{wt} \% \mathrm{Sn}[4]$, the $\beta-\mathrm{Sn} / \alpha-\mathrm{Zn}$ eutectic fraction decreases with decreasing alloy $S n$ content. On the basis proposed by Crocker et al. [10] and later confirmed by Vnuk et al. [11], the Sn-Zn eutectic appears as

\footnotetext{
* Corresponding author.

E-mail address: spinelli@ufscar.br (J.E. Spinelli).
} 

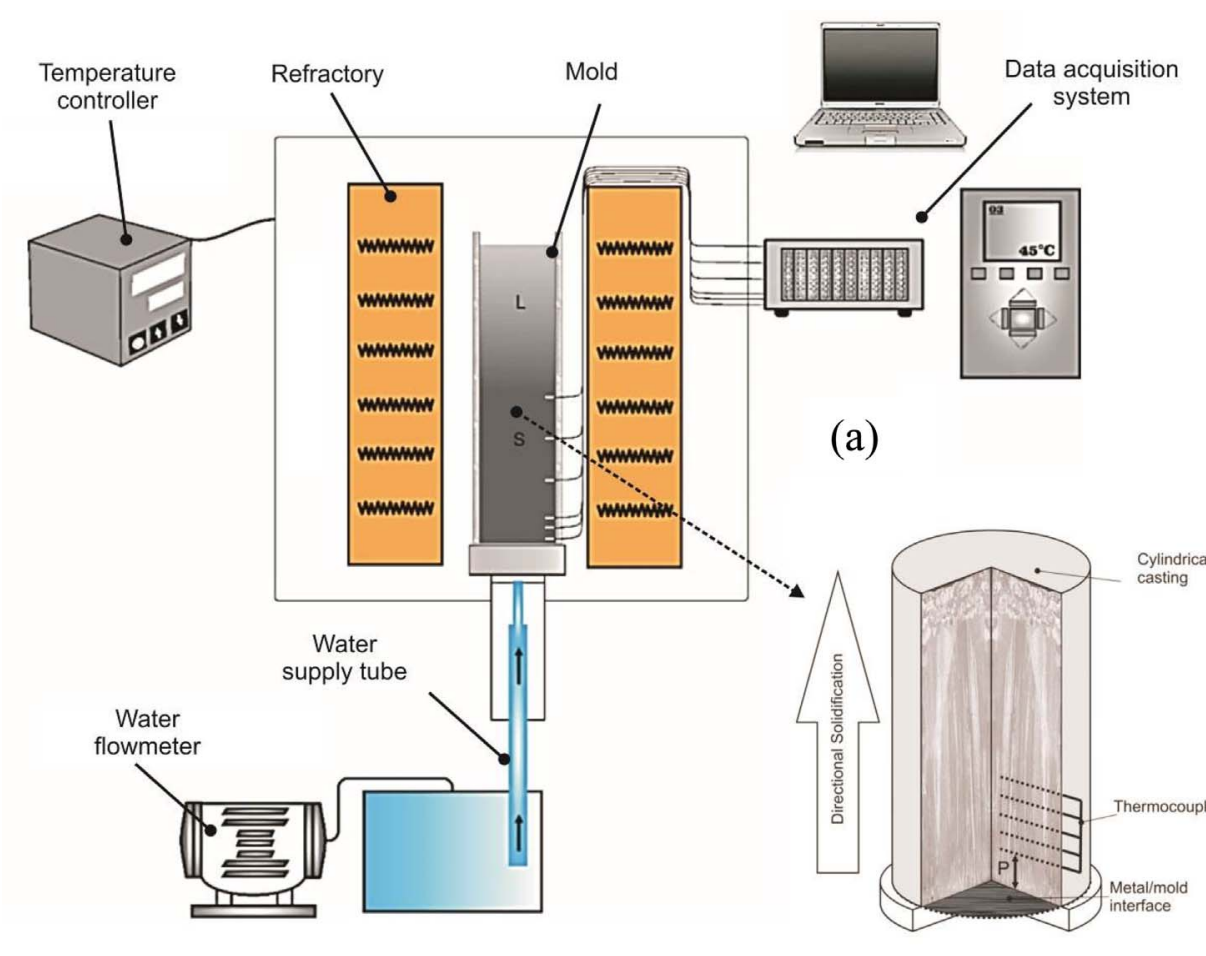

Fig. 1. (a) Vertical upward directional solidification casting assembly used to produce the directionally solidified Zn-Sn alloys castings; and (b) method detailing the removal of specimens for tensile tests.
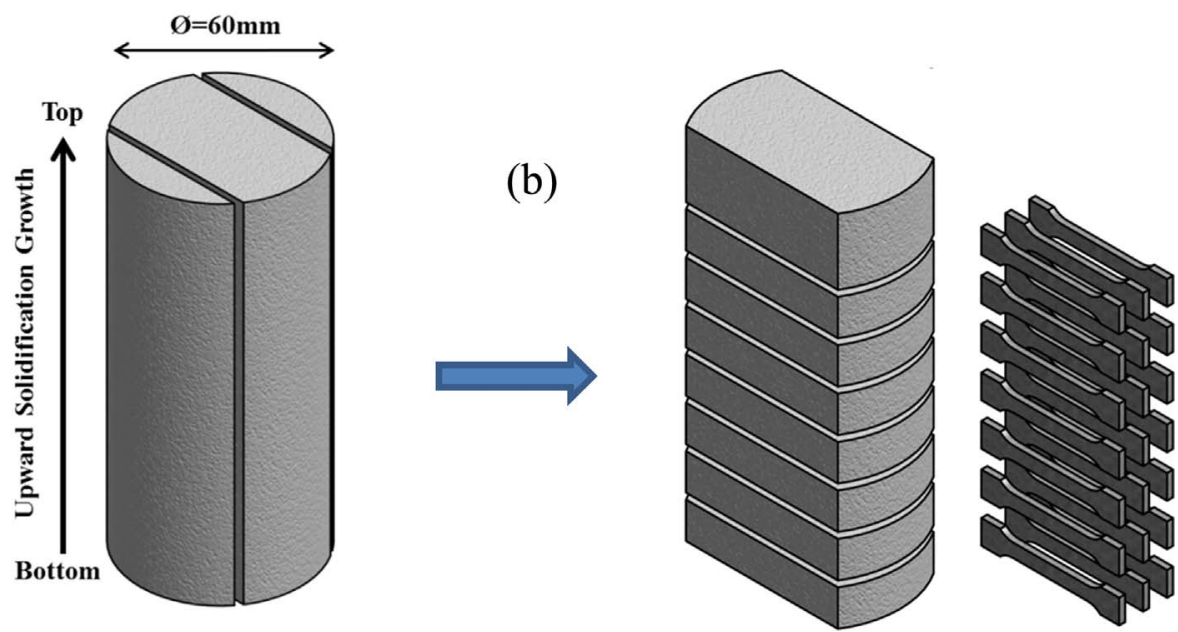

"broken-lamellae", with the volume fraction of the faceting Zn lamellar phase being $8.3 \%$, with the other phase being non-faceted. It has been shown that the Zn-lamellae grow unevenly, being irregularly perforated under stationary cooling conditions [11]. The eutectic spacing, $\lambda_{\mathrm{E}}$, was reported to be less sensitive to growth rate (v) variations than expected, that is, the evolution of $\lambda_{\mathrm{E}}$ does not obey the classical $\lambda_{\mathrm{E}}{ }^{2} \mathrm{v}=$ constant equation $[11,12]$ for the growth of lamellar eutectics.

The aim of this research work is to gain insight into microstructural length-scales variations of both the eutectic mixture and the Zn-rich plate-like cells considering broad ranges of both solidification cooling rates/growth rates and $\mathrm{Sn}$ content of $\mathrm{Zn}$-Sn alloys. For this, transient directional solidification experiments will be carried out with Zn-10, 20 and $40 \mathrm{wt} \% \mathrm{Sn}$ alloys. Once in possession of these findings, the effect of microstructural features, such as the local length scales of the phases, on tensile properties and fracture mechanisms will be discussed.

\section{Experimental procedure}

Three hypoeutectic Zn-10, 20 and $40 \mathrm{wt} \% \mathrm{Sn}$ alloys have been assessed, with three directionally solidified (DS) castings being produced by using a water-cooled unsteady-state solidification setup, as shown in Fig. 1(a) $[13,14]$. The surface of the carbon steel bottom-part mold has been finished with a 1200 grit SiC abrasive paper. The following procedures were performed for each alloy: firstly, the alloy was melted in situ by radial electrical wiring positioned around a cylindrical stainless-steel container. Secondly, when the melt temperature was about $10 \%$ above the alloy liquidus temperature, the electric heaters were disconnected and at the same time the water flow at the bottom of the container was started, permitting the onset of solidification. Finally, the evolution of temperatures along the length of the DS casting was monitored by a number of fine type $\mathrm{J}$ thermocouples $(0.2 \mathrm{~mm}$ diameter wire), placed in the geometrical center of the cylindrical mold cavity along its length. The temperature-time records were stored with a view to permitting the cooling rates and growth rates to be determined from the cooled bottom to the top of the castings [15].

SEM analyses in both Secondary Electrons (SE) and Back-scattered Electron (BSE) modes were carried out in the DS samples. So, micrographs referring to various positions along the length of the $\mathrm{Zn}-\mathrm{Sn}$ 
(a)

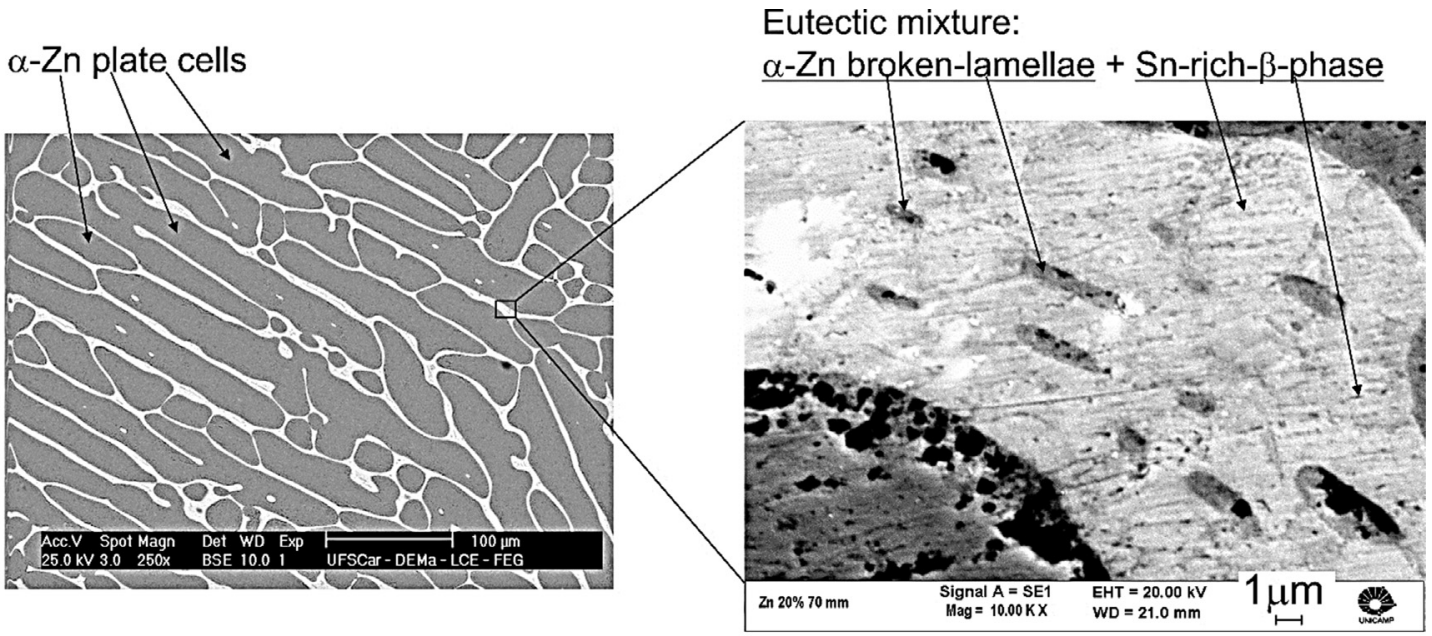

(b)
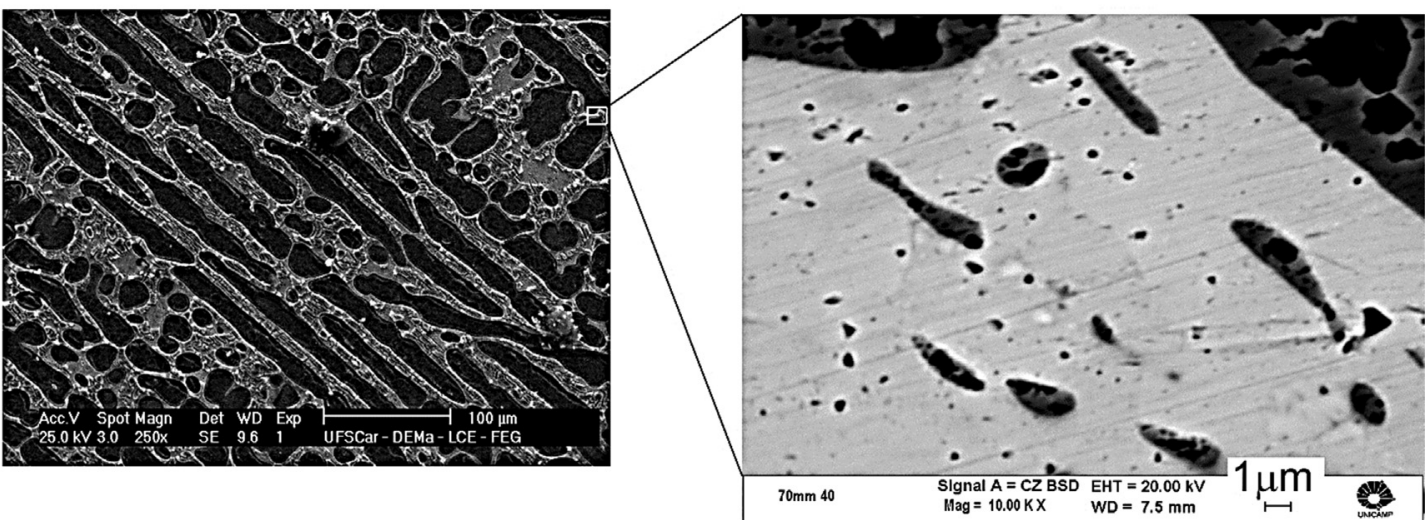

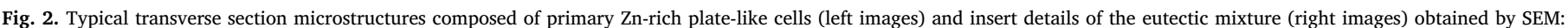
directionally solidified (a) Zn-20 wt\% Sn and (b) Zn-40 wt\% Sn alloys.

alloys castings were obtained using both a Field Emission Gun (FEG) Scanning Electron Microscope SEM-EDS FEI (Inspect S50L) and a Zeiss SEM (Zeiss-EVO-MA15). Measurements on the as-solidified microstructures at various positions were performed using the line intercept method $[16,17]$ for eutectic $\left(\lambda_{E}\right)$ and cellular $(\lambda)$ spacings.

Each position chosen for tensile tests along the length of the DS castings allowed three specimens to be extracted so that average tensile properties regarding strength and ductility and their standard deviations could be determined. Fig. 1(b) shows the scheme employed to extract the tensile specimens from the DS Zn-Sn alloys castings. The specimens were subjected to tensile tests using a MTS 810 machine, according to specifications of the ASTM Standard E $8 \mathrm{M} / 04$ at a strain rate of $3 \times 10^{-3} \mathrm{~s}^{1}$.

\section{Results and discussion}

Fig. 2 shows some representative SEM microstructures of the DS Zn20 and $40 \mathrm{wt} \% \mathrm{Sn}$ alloys castings. The dark and bright phases (left-side images) are the primary $\alpha-Z n$ and the eutectic $S n-Z n$ phases, respectively. The eutectic phases enveloping the Zn-rich plate cells can be seen in more details by examining the SEM images at the right-side of Fig. 2. Also, the eutectic morphology in all samples examined may be identified as a broken-lamellar structure.

A related point to consider on the left images of Fig. 2, is that as the alloy Sn content increases, the volume fraction of the eutectic Sn-Zn mixture also increases. A collection of microstructures emphasizing either the primary phase or the eutectic has been examined along the length of the three Zn-Sn alloys castings, so that local spacings between the phases could be outlined. The average cellular spacing, for instance, varied from $15 \mu \mathrm{m}$ to $60 \mu \mathrm{m}$ for the $\mathrm{Zn}-10$ and $20 \mathrm{wt} \% \mathrm{Sn}$ alloys whereas it varied from $10 \mu \mathrm{m}$ to $45 \mu \mathrm{m}$ for the $\mathrm{Zn}-40 \mathrm{wt} \% \mathrm{Sn}$ alloy. The eutectic spacing varied from 1.1 to $2.9 \mu \mathrm{m}$ and from 1.6 to $3.5 \mu \mathrm{m}$ for the $\mathrm{Zn}$ $20 \mathrm{wt} \% \mathrm{Sn}$ and $\mathrm{Zn}-40 \mathrm{wt} \% \mathrm{Sn}$ alloys, respectively. This means that although finer plate cells can be formed in the $\mathrm{Zn}-40 \mathrm{wt} \% \mathrm{Sn}$ alloy casting, they can be associated with slightly coarser eutectic mixtures.

Considering that the fraction of eutectic formed in the $\mathrm{Zn}-10 \mathrm{wt} \% \mathrm{Sn}$ alloy is negligible, only two compositions have been adopted to establish the variation of eutectic spacing with the growth rate, as can be seen in Fig. 3. The plots of ' $\log \lambda_{\mathrm{E}}$ ' against 'log v' yielded straight lines to be adjusted. As reported by Vnuk et al. [11], a slope of -0.40 was

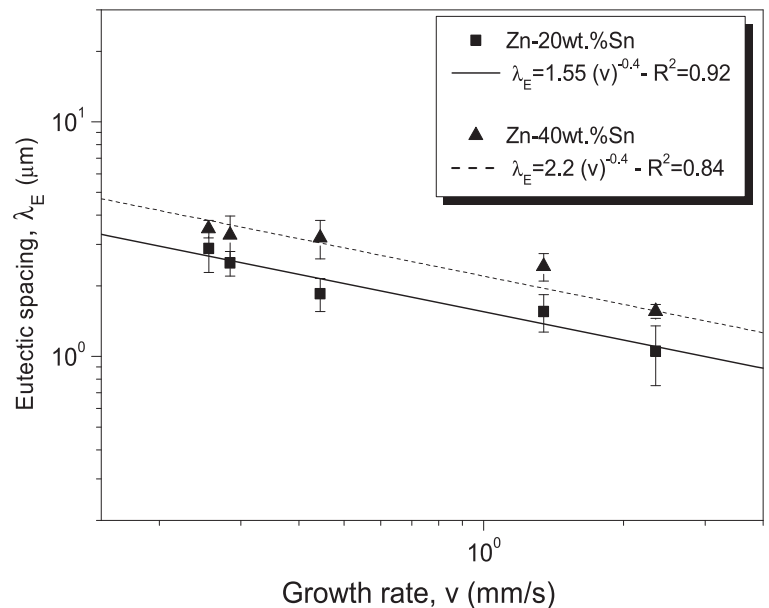

Fig. 3. Eutectic spacing as a function of growth rate (v) for the $\mathrm{Zn}$-Sn alloys. $\mathrm{R}^{2}$ is the coefficient of determination. 


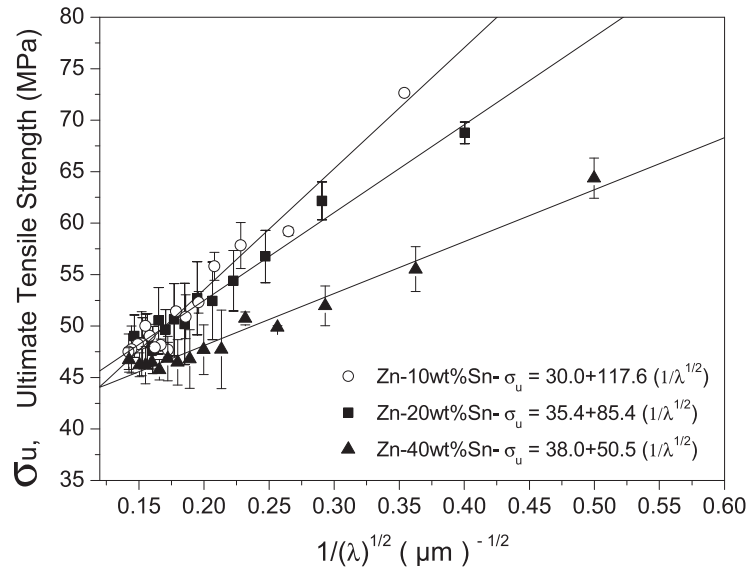

(a)

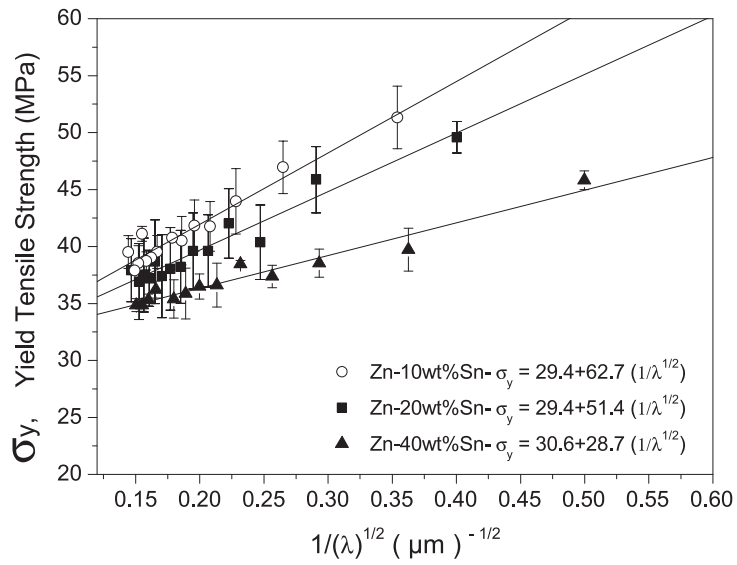

(b)

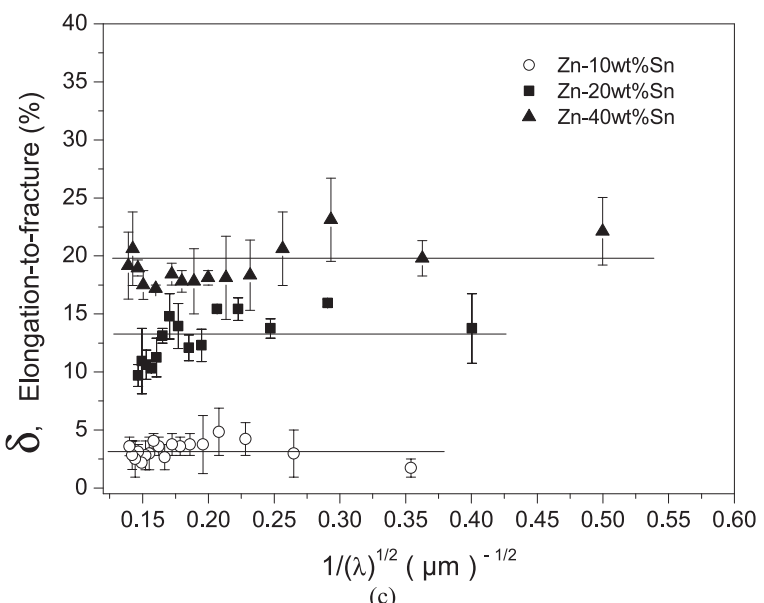

(c)

Fig. 4. (a) Ultimate tensile strength- $\sigma_{u}$, (b) Yield tensile strength- $\sigma_{y}$ and (c) elongation-tofracture- $\delta$ as a function of the cellular spacing, $\lambda$, for the $\mathrm{Zn}$-Sn alloys. Horizontal lines inside the graphs in (c) are average values obtained for each alloy evaluated.

found to be representative of both experimental scatters. Despite the transient heat flow regime and higher growth rates related to the present experiments, the same exponent determined for stationary solidification conditions [11] can also be applied. This exponent characterizes the $\lambda_{E} \times v$ growth relationship for $S n-Z n$ eutectics. Furthermore, the increase in the alloy Sn content is shown to increase $\lambda_{E}$ values to about $40 \%$, which demonstrates a solute-induced coarsening effect for the eutectic structure.

Fig. 4(a) and (b) show the evolutions of the ultimate tensile strength and the yield strength, respectively, with the inverse of the square root of the cellular spacing, $\lambda$, for the three $\mathrm{Zn}$-Sn alloys examined. For all cases, smaller $\lambda$ values (i.e., increase in $\lambda^{-1 / 2}$ ) resulted in higher strength. The most remarkable variation is worth noted in the results associated with the DS $\mathrm{Zn}-10 \mathrm{wt} \% \mathrm{Sn}$ alloy casting. In this case, $\sigma_{\mathrm{u}}$ varied from 47.5 to $72.5 \mathrm{MPa}$ for maximum and minimum experimental values of $\lambda$, respectively. The increase in strength is related to the manner that the refined microstructure makes the dislocation pile-up more efficient during deformation. Smaller spacing means a better distribution of the harder $\mathrm{Zn}$-rich phase throughout the microstructure. Furthermore, less $\mathrm{Sn}$ in the $\mathrm{Zn}$-Sn alloy means increase in the volume fraction of primary Zn-rich plate cells, thus contributing to increase in the tensile strength, as observed in Fig. 4(a) and (b). Based on the lever rule, fractions of the primary $\mathrm{Zn}$-rich cells can be estimated as being $89 \%, 78 \%$ and $56 \%$ for the $\mathrm{Zn}-10 \mathrm{wt} \% \mathrm{Sn}, \mathrm{Zn}-20 \mathrm{wt} \% \mathrm{Sn}$ and $\mathrm{Zn}-40 \mathrm{wt} \%$ Sn alloys, respectively.

As can be seen in Fig. 4(c), the microstructural refinement does not affect the elongation-to-fracture. So, horizontal lines roughly represent mean $\delta$ values related to the different experimental values of $\lambda$. However, the alloy $S n$ content remarkably affects the ductility. This is explained by the increase in the volume fraction of soft tin, as part of the eutectic mixture, with the increase in the alloy Sn content.

Fig. 5 shows typical SEM fracture surfaces of the Zn-Sn alloys of specimens corresponding to positions very close to the cooled bottom of the DS castings. It is worth noting that a cleavage mode of fracture is present in all microstructures. Alveolar structures or dimples also appear in all SEM images where it can be seen that they increase as the alloy $\mathrm{Sn}$ content is increased, i.e., from Fig. 5(a) to (c).

Considering that the microstructures of the $\mathrm{Zn}-\mathrm{Sn}$ alloys are formed by primary $\alpha-Z n$ plate cells surrounded by the eutectic mixture, as the alloy $\mathrm{Zn}$ content decreases, the fraction of the primary $\alpha$ - $\mathrm{Zn}$ phase decreases and that of the eutectic Sn-Zn mixture increases. The higher proportion of dimples is perfectly coherent with the higher proportion of eutectic mixture on the alloy microstructure. It seems that during tensile loading of a $\mathrm{Zn}$-Sn specimen the primary $\mathrm{Zn}$-rich plates tend to crack by a cleavage mode while the eutectic structure within the intercellular region is able to flow in a ductile manner giving origin to the dimples. Consequently, higher values of ductility are associated with higher Sn content (see Fig. 4(c)).

Farihan and co-authors [1] examined the effects of minor additions of $\mathrm{Ag}$ on the fracture mechanisms of $\mathrm{Zn}-20 \mathrm{wt} \% \mathrm{Sn}(-\mathrm{xAg})$ alloys. $\mathrm{A}$ mixed-mode fracture has been reported to the alloy containing $0.50 \mathrm{wt}$ $\% \mathrm{Ag}$ with prevalence of a ductile failure, while the other two compositions having 0.27 and $0.03 \mathrm{wt} \% \mathrm{Ag}$ showed a brittle failure. It was observed that both alloys ( 0.27 and $0.03 \mathrm{wt} \% \mathrm{Ag})$ exhibited a smooth flat fracture surface, cleavage regions and absence of dimples. In the present study, both modes of fracture, i.e., cleavage and dimples occur.

Some of the dimples depicted in Fig. 5 are deep with lateral walls containing Sn-rich eutectic phase, which flowed during plastic deformation. The bottom part of the dimple is probably constituted by $\mathrm{Zn}$ rich eutectic, which gives origin to cracks initiating the formation of dimples. Sn-rich triple points, also known as crows' feet marks, can be noted in Fig. 5(c) (SEM image at right). This is due to the local ductile behavior indicating flow of the material until the local cross-sectional area attains zero, provoking disconnection of the parts.

Jovanovic et al. [18] studied aspects of fracture surfaces on as-cast water-quenched and furnace-cooled $\mathrm{Zn}$-Al specimens. They also reported the occurrence of mixed-mode fracture in their samples. Deep voids are reported to be visible in the fracture surface of the as-cast samples. A mixed- mode fracture was shown to be associated with the fracture surface of the furnace-cooled specimen, i.e. together with shallow dimples, intergranular brittle fracture occurs.

Liu et al. [19] observed that small grain size structures may lead polycrystalline $\mathrm{Zn}$ to fail from tearing cracks developed along the grain boundaries. Further, coalescing cavities that nucleated at triple junctions have been reported, which gave rise to ductile inter-crystalline fracture. This seems to be the case of the present study, since a higher proportion of ductile patterns within the fracture surface are associated 

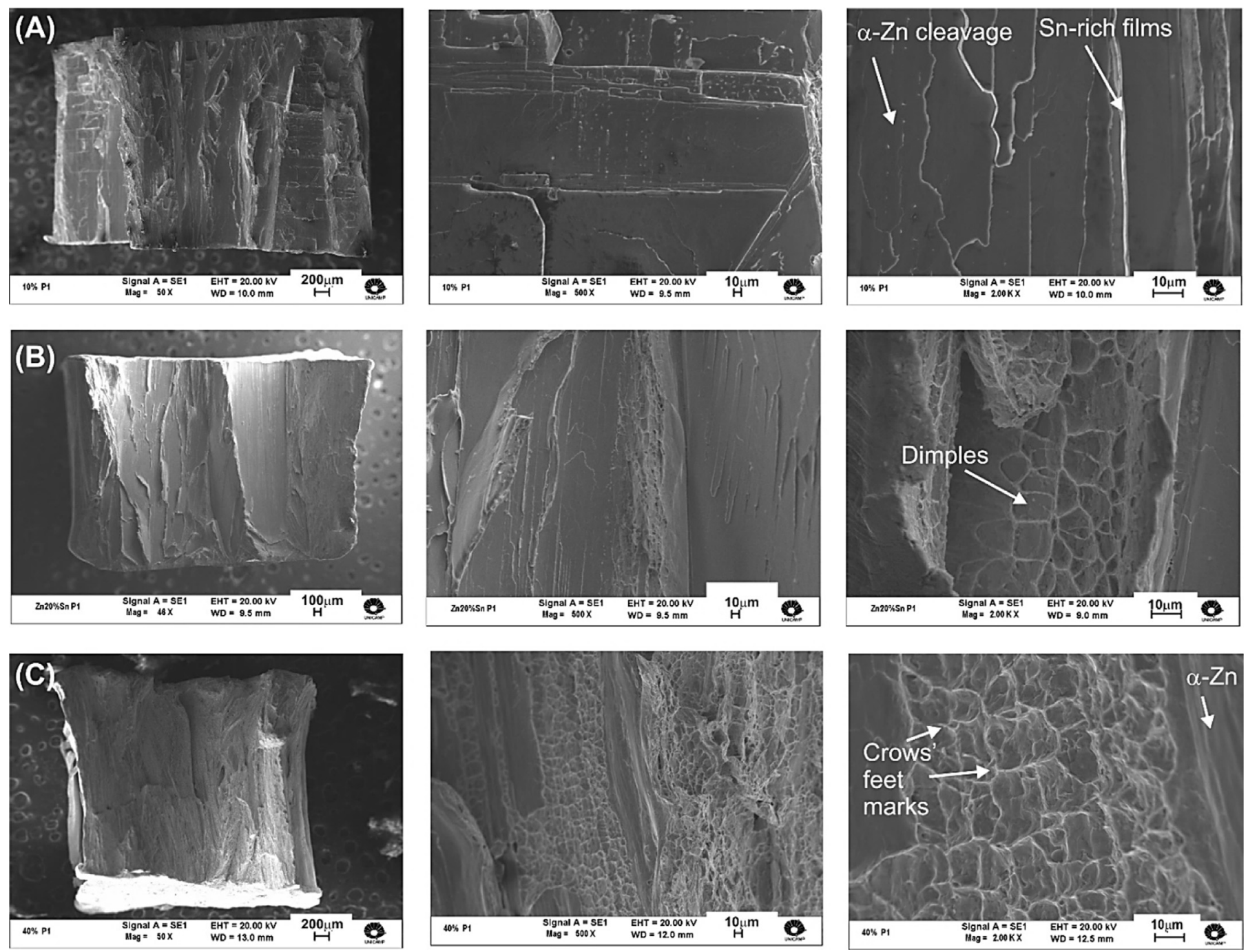

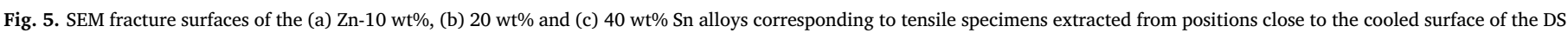
castings. In all cases, the corresponding cooling rate during directional solidification is about $10 \mathrm{~K} / \mathrm{s}$.

with the alloy characterized by the smallest fraction of Zn-rich cells, i.e., the $\mathrm{Zn}-40 \mathrm{wt} \% \mathrm{Sn}$ alloy.

\section{Conclusions}

The microstructures of the Zn-Sn alloys examined were shown to be formed by primary $\alpha$-Zn plate-like cells surrounded by a eutectic mixture $(\alpha-Z n / \beta-S n)$ having a broken-lamellar structure. Growth laws, $\lambda_{E}=$ $\mathrm{a} \mathrm{v}^{-0.4}$, were shown to represent the evolution of the eutectic spacing during growth both under transient and steady-state solidification conditions, where a is a constant that increases with the increase of the alloy $\mathrm{Sn}$ content. Hall-Petch type correlations are proposed relating the yield, $\sigma_{\mathrm{y}}$, and ultimate tensile strengths, $\sigma_{\mathrm{u}}$. to the cellular spacing, $\lambda$, in which smaller $\lambda$ values resulted in both higher $\sigma_{\mathrm{y}}$ and $\sigma_{\mathrm{u}}$. The most remarkable variation $\sigma_{\mathrm{u}}$ vs. $\lambda$ has been shown to be associated with the DS $\mathrm{Zn}-10 \mathrm{wt} \% \mathrm{Sn}$ alloy casting. In this case, $\sigma_{\mathrm{u}}$ varied from 47.5 to $72.5 \mathrm{MPa}(52.6 \%)$. A mixed-mode fracture characterized the tensile specimens, in which the Zn-rich plates were shown to crack by a cleavage mode, while the eutectic structure in a ductile manner giving origin to dimples.

\section{Prime novelty statement}

Hypereutectic $\mathrm{Zn}$-Sn alloys are considered $\mathrm{Pb}$-free solders alternatives to replace $\mathrm{Pb}-\mathrm{Sn}$ alloys. Here, a variety of applications is possible: assembling optical parts, circuit boards in automobiles and circuit modules for step soldering.

The present study is focused on the elucidation of two key aspects involving hypoeutectic Zn-Sn alloys, which are i. the size, shape and distribution of Zn-Sn eutectic structure under transient solidification conditions by varying either cooling rate or Sn content; and ii. the effects of eutectic structures and their proportions on the mode of fracture of Zn-Sn alloys. This is the first time these results are being reported.

The present findings in Zn-Sn alloys allow appropriate coupling of cooling rate/Sn content (processing parameters), cellular/eutectic spacing (microstructure parameters) and mechanical behavior (application properties).

\section{Acknowledgements}

The authors acknowledge the financial support provided by FAPESP (São Paulo Research Foundation, Brazil: grants 2016/10596-6; 2017/ 12741-6; 2017/15158-0), CNPq and CAPES. 


\section{References}

[1] F.M. Azizan, H. Purwanto, M.Y. Mustafa, Effect of adding Ag on tensile and microstructure properties of zinc alloy, IJET-IJENS 12 (2012) 78-84.

[2] M.A.M. Arif, M.Z. Omar, N. Muhamad, Production of nondendritic semisolid ZA3 alloy through heat treatment, J. Appl. Sci. 11 (2011) 323-329.

[3] W.L.R. Santos, C. Brito, J.M.V. Quaresma, J.E. Spinelli, A. Garcia, Plate-like cell growth during directional solidification of a Zn-20wt $\% \mathrm{Sn}$ high-temperature leadfree solder alloy, Mater. Sci. Eng. B 182 (2014) 29-36.

[4] K. Suganuma, S. Kim, K. Kim, High-temperature lead-free solders: properties and possibilities, JOM 61 (2009) 64-71.

[5] G. Zeng, S. McDonald, K. Nogita, Development of high-temperature solders, Microelectron. Reliab. 52 (2012) 1306-1322.

[6] J.E. Lee, K.S. Kim, K. Suganuma, J. Takenaka, K. Hagio, Interfacial properties of Zn-Sn alloys as high temperature lead-free solder on Cu substrate, Mater. Trans. 46 (2005) 2413-2418.

[7] J.E. Lee, K.S. Kim, K. Suganuma, M. Inoue, G. Izuta, Thermal properties and phase stability of Zn-Sn and Zn-In alloys as high temperature lead-free solder, Mater. Trans. 48 (2007) 584-593.

[8] G.M. Hughes, G.E. Smith, P.E.J. Flewitt, A.G. Crocker, The brittle fracture of polycrystalline zinc, Proc. R. Soc. A 463 (2007) 2129-2151.

[9] N.M. Giallourakis, d.K. Matlock, G. Krauss, A cryogenic fracture technique for characterizing zinc-coated steels, Metallography 23 (1989) 209-218.

[10] M.N. Crocker, R.S. Fidler, R.W. Smith, The characterization of eutectic structure,
Proc. R. Soc. A 335 (1973) 15-37.

[11] F. Vnuk, M. Sahoo, D. Baragar, R.W. Smith, Mechanical properties of the Sn-Zn eutectic alloys, J. Mater. Sci. 15 (1980) 2573-2583.

[12] K.A. Jackson, J.D. Hunt, Lamellar and rod eutectic growth, Trans. Metall. Soc. AIME 236 (1966) 1129-1142.

[13] R.V. Reyes, T.S. Bello, R. Kakitani, T.A. Costa, A. Garcia, N. Cheung, J.E. Spinelli, Tensile properties and related microstructures aspects of hypereutectic Al-Si alloys directionally solidified under different melt superheats and transient heat flow conditions, Mater. Sci. Eng. A 685 (2017) 235-243.

[14] A.P. Silva, J.E. Spinelli, N. Mangelinck-Noel, A. Garcia, Microstructural development during transient directional solidification of Al-Bi alloys, Mater. Des. 31 (2010) 4584-4591.

[15] T.A. Vida, E.S. Freitas, C. Brito, N. Cheung, M.A. Arenas, A. Conde, J. Damborenea, A. Garcia, Thermal parameters and microstructural development in directionally solidified Zn-rich Zn-Mg alloys, Metall. Mater. Trans. 47 (2016) 3052-3064.

[16] M. Gunduz, E. Cadirli, Directional solidification of aluminium-copper alloys, Mater. Sci. Eng. A 327 (2002) 167-185.

[17] E. Çadirli, U. Büyük, S. Engin, H. Kaya, Effect of silicon content on microstructure, mechanical and electrical properties of the directionally solidified Al-based quaternary alloys, J. Alloy. Compd. 694 (2017) 471-479.

[18] M.T. Jovanović, I. Bobić, B. Djurić, N. Grahovac, N. Ilić, Microstructural and sliding wear behaviour of a heat-treated zinc-based alloy, Tribol. Lett. 25 (2007) 173-184.

[19] J.H. Liu, C.X. Huang, S.D. Wu, Z.F. Zhang, Tensile deformation and fracture behaviors of high purity polycrystalline zinc, Mater. Sci. Eng. A 490 (2008) 117-125. 